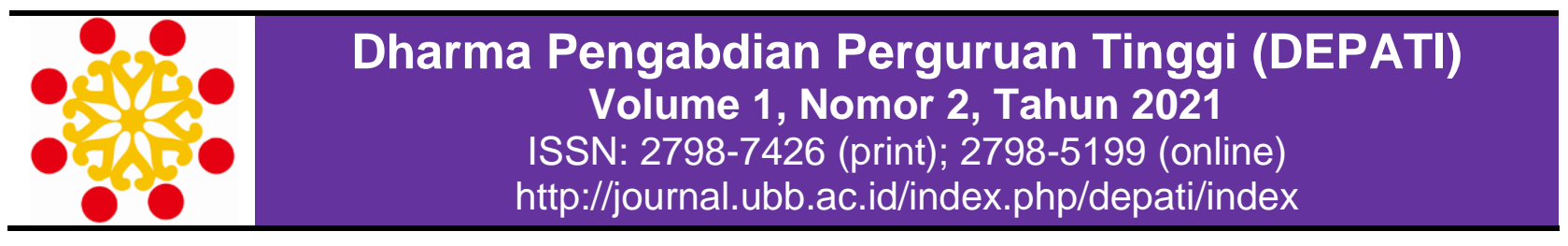

\title{
PEMBENTUKKAN KELOMPOK UMKM SEBAGAI UPAYA PEMETAAN JENIS USAHA UNTUK MEMPERMUDAH KEGIATAN PEMBERDAYAAN MASYARAKAT DI DESA TONGGORISA
}

\author{
Sri Ernawati*), M. Rimawan, Jaenab, M. Yusuf, dan Saidnil Aksa \\ Sekolah Tinggi Ilmu Ekonomi Bima \\ Jalan Wolter Monginsidi, Komplek Tolobali, Kelurahan Sarae, Kota Bima, NTB \\ *E-mail korespondensi: sriernawati.stiebima@gmail.com
}

\begin{abstract}
Info Artikel: Abstract
Dikirim:

2 Oktober 2021

Revisi:

23 November

2021

Diterima:

29 November

2021

Kata Kunci:

UMKM,

pelatihan,

At present, MSMEs play an important role in the national economy. The contribution of MSMEs cannot be underestimated in the development of the business industry in the region. The purpose of the service carried out is to map business groups so that empowerment through training can be directed appropriately in accordance with the problems that occur in MSMEs. The methods used in community service this time include 1) Observing business actors, 2) interviews with community business owners, 3) documenting activities, 4) Training to improve community capabilities. After the MSME group was formed, trainings were conducted. The results of this service were the formation of the MSME group, mapping of MSMEs to facilitate empowerment carried out, the training provided in accordance with the problems experienced by MSMEs such as product innovation training, marketing with digital marketing and simple bookkeeping. . So from this service activity, we hope that Tonggorisa Village can become a prosperous and independent village.
\end{abstract}

pemberdayaan

\begin{abstract}
Abstrak
Pada saat sekarang UMKM memainkan peranan penting dalam perekonomian nasional. Kontribusi UMKM tidak tidak bisa dipandang sebelah mata dalam perkembangan industry bisnis di daerah. Tujuan pengabdian yang dilakukan untuk melakukan pemetaan kelompok usaha agar pemberdayaan melalui pelatihanpelatihan bisa terarah dengan tepat sesuai dengan permasalahan yang terjadi pada UMKM. Metode yang digunakan dalam pengabdian kepada masyarakat kali ini antara lain 1) Melakukan observasi kepada pelaku usaha, 2) wawancara dengan masyarakat pemilik usaha, 3) dokumentasi kegiatan, 4) Pelatihan untuk meningkatkan kemampuan masyarakat. Setelah Kelompok UMKM terbentuk dilakukan pelatihapelatihan, Hasil dari pengabdian ini adanya pembentukkan kelompok UMKM, pemetaan UMKM untuk mempermudah pemberdayaan yang dilakukan, pelatihapelatihan yang diberikan sesuai dengan permasalahan yang dialami UMKM seperti pelatihan inovasi produk, pemasaran dengan digital marketing dan pembukuan sederhana. Sehingga dari kegiatan pengabdian ini harapan kami Desa Tonggorisa bisa menjadi desa sejahtera dan mandiri.
\end{abstract}

\section{PENDAHULUAN}

Perguruan tinggi sebagai agent of change, salah satunya Sekolah Tinggi Ilmu Ekonomi Bima (STIE Bima) selalu mengupayakan salah satu bentuk Tri Dharma Perguruan Tinggi yaitu Pengabdian Kepada Masyarakat dengan menjadikan UMKM sebagai mitra yang akan dibina dengan memeberikan pelatihan, membantu kegiatan pemasaran sampai manajemen usaha yang digeluti. Setiap kegiatan KKN yang dilaksanakan oleh mahasiswa selalu berkaitan dengan kewirausahaan, dimana mahasiswa mampu menggali potensi yang dimiliki daerah tujuan KKN untuk dikelola dengan memberikan inovasi pada potensi tersebut untuk meningkatkan ekonomi kreatif masyarakat. 
Kedudukan UMKM dalam perekonomian Indonesia sangat strategis dibandingkan dengan usaha besar. Kedudukan tersebut dapat dilihat dalam tiga sisi. Pertama, dari sisi jumlah unit usaha, UMKM mencapai 99\% dengan dinominasi oleh usaha mikro sebesar 97,79\%. Kedua, dari sisi penyerapan tenaga kerja, UMKM mampu menyerap sebesar 96,70\% yang didominasi oleh usaha mikro sebesar 90,12\%. Ketiga, dari sisi kontribusi PDB, UMKM mampu menyumbang sebesar 59,08\% juga didominasi oleh usaha mikro sebesar 35,81\% [1]

Seperti dikutip dari penyataan Sekretaris Kementerian Koperasi dan UKM Arif Rahman Hakim, usai berdialog dengan Deputi Bidang Statistik Sosial Biro Pusat Statistik (BPS) Ateng Hartono, di Jakarta, menyatakan bahwa Jumlah pelaku usaha mikro dan kecil memang mengalami perubahan sebagai akibat dampak pandemi Covid-19Namun, perubahan tersebut tidak sampai terjadi penurunan hingga 30 juta pelaku usaha. Menurut Arif, perkembangan jumlah pelaku usaha mikro dan usaha kecil dapat diketahui dengan pendekatan data yang bersumber dari Survei Angkatan Kerja Nasional (Sakernas) Badan Pusat Statistik (BPS) tahun 2019 dan 2020. Dengan begitu, Arif memastikan bahwa data yang ada adalah valid. Tercatat pelaku usaha mikro informal baik yang berusaha sendiri tanpa dibantu buruh maupun dibantu buruh tidak tetap pada 2020 bertambah 1,18 juta orang (2,62 persen) dari 45,07 juta orang pada 2019 menjadi 46,25 juta orang pada 2020 [2]

Data Dinas Koperasi dan UKM Kabupaten Bima menyalurkan bantuan bantuan produktif usaha mikro (BPUM) kepada16.603 UMKM, [3]. Data tersebut menunjukkan bahwa di Kabupaten Bima jumlah UMKM yang tercatat masih belum banayk jika dilihat dari luas wilayah dan jumlah penduduk kabupaten bima yang banyak yaitu 532.677 jiwa. sehingga pertemunguhan jumlah UMKM sangat berperan penting karena peranan UMKM dalam perekonomian Indonesia sangat penting dalam menyediakan lapangan pekerjaan dan menghasilkan output yang berguna bagi masyarakat

Selain memiliki peran yang positif dalam pertumbuhan ekonomi dan penyerapan tenaga kerja, UMKM juga berperan dalam pendistribusian hasil-hasil pembangunan sehingga UMKM mampu mendukung pemerataan hasil pembangunan ekonomi. Keberadaan sektor Usaha Mikro Kecil, dan Menengah bukan hanya dianggap sebagai tempat penampungan sementara bagi para pekerja yang belum masuk ke sektor formal, tetapi juga sebagai motor pertumbuhan aktivitas ekonomi. Sehingga pengembangan dan pemberdayaan UMKM menjadi pilihan strategis untuk meningkatkan pendapatan kelompok masyarakat berpendapatan rendah, dalam rangka mengurangi kesenjangan pendapatan dan kemiskinan melalui peningkatan kapasitas usaha dan keterampilan pengelolaan usaha.[4]

Kedudukan strategis yang dimiliki oleh UMKM tidak menjamin usaha tersebut terlepas dari berbagai masalah dalam perkembangannya. Biasanya masalah yang masih dihadapi terkait dengan sulitnya permodalan, kurangnya pasokan bahan baku produksi, sulitnya memasarkan hasil, sulit, terbatasnya sumber energi, terbatasnya akses informasi, kurang tersedianya infrastruktur, ketersediaan teknik dan keahlian, pengaruh inflasi, dan masalah lingkungan. Semua masalah ini menjadi penghalang perkembangan dan daya saing UMKM di Indonesia, sehingga pemerintah perlu secara terus menerus melakukan pembinaan terhadap UMKM. [5]

UMKM merupakan suatu usaha yang potensial bagi perkembangan perekenomian di Indonesia sehingga dalam pelaksanaannya perlu dioptimalkan dan digali kembali potensipotensi yang ada untuk peningkatan pembangunan ekonomi masyarakat. Pengembangan ini tentu saja akan lebih berkembang dengan baik dengan adanya dukungan dari pemerintah dalam memberikan fasilitas-fasilitas yang diperlukan sebagai penunjang pelaksanaan dan kemajuan usaha yang dijalankan agar dapat menghasilkan kualitas produksi yang baik sehingga dapat bersaing Sekarang banyak pembinaan dan pemberdayaan yang dilakukan oleh berbagai lembaga, baik pemerintah maupun swasta, belum terpadu dan terkoordinasikan dengan baik. Kegiatan bersifat sektoral dan terkotak-kotak. Pelaku usaha mikro dan kecil cenderung diperlakukan hanya sebagai obyek binaan, sedangkan lembaga penyelenggara hanya mementingkan sasaran dan target yang ingin dicapai [6]

Desa Tonggorisa Kecamatan Palibelo Kabupaten Bima, Nusa Tenggara Barat yang terletak di koordinat 118.719681 BT / -8.528564 LS memiliki luas wilayah 340 ha. Dengan jumlah penduduk per Agustus 2021 sebanyak 1.854 jiwa. Sebagian besar masyarakatnya bekerja sebagai petani. Keadaan usaha di Desa Tonggorisa masih belum dipetakan sesuai dengan jenis usaha masyarakat agar ketika bantuan atau kegiatan pelatihan dilaksanakan bisa 
lebih mudah dan manajemen kegiatan lebih terarah sesuai dengan jenis usaha masyarakatnya. Ada beberapa masalah yang ditemuan di Desa Tonggorisa seperti usaha yang sudah lama dilakukan oeh masyarakat belum mempunyai wadah atau kelompok, sehinggan usaha mereka masih individu dan sulit mendapatkan bantuan karena bantuan dari pemerintah daerah biasanya untuk kelompok usaha bukan usaha individu, setiap UMKM memiliki permasalahan yang berbeda-beda seperti UMKM kerupuk singkong belum ada inovasi produk, mereka mulai dari mengenal usaha sampai sekarang hanya membuat kerupuk singkong yang ukurannya besar dengan rasa yang original, untuk UMKM kios, bedek dan pembuatan tahu permasalahan terbesar terkait dengan alokasi keuangan yang belum bisa membedakan antara keuangan untuk usaha dan keperluan rumah tangga. untuk itu pengabdian yang kami lakukan dengan "Pembentukkan Kelompok UMKM Sebagai Upaya Pemetaan Jenis Usaha Untuk Mempermudah Kegiatan Pemberdayaan Masyarakat Di Desa Tonggorisa".

\section{METODE PELAKSANAAN}

Metode yang digunakan pada pengabdian kepada masyarakat kali ini antara lain: melakukan observasi ke masyarakat yang memiliki usaha, melakukan wawancara mandalam dengan masyarakat pemilik usaha terkait dengan jenis usaha, modal awal, pendapatan bulanan, pangsa pasar, jumlah tenaga kerja samapi permasalah yang dihadapi selama menjalankan usaha, dokumentasi, setiap kegiatan yang dilakukan didokumentasikan agar mempermuda saat pelaporan kegiatan dan keakuratan data saat survey dan wawancara dilakukan. Dokumentasi dilakukan denga memfoto dan rekaman saat wawancara. Kegiatan pelatihan yang dilakukan seperti pelatihan inovasi produk, pemasaran terkait kualitas produk, kemasan, label produk dan digital marketing serta pembukuan sederhana. Tahapan pelaksanaan kegiatan tersebut tertuang dalam Gambar 1.

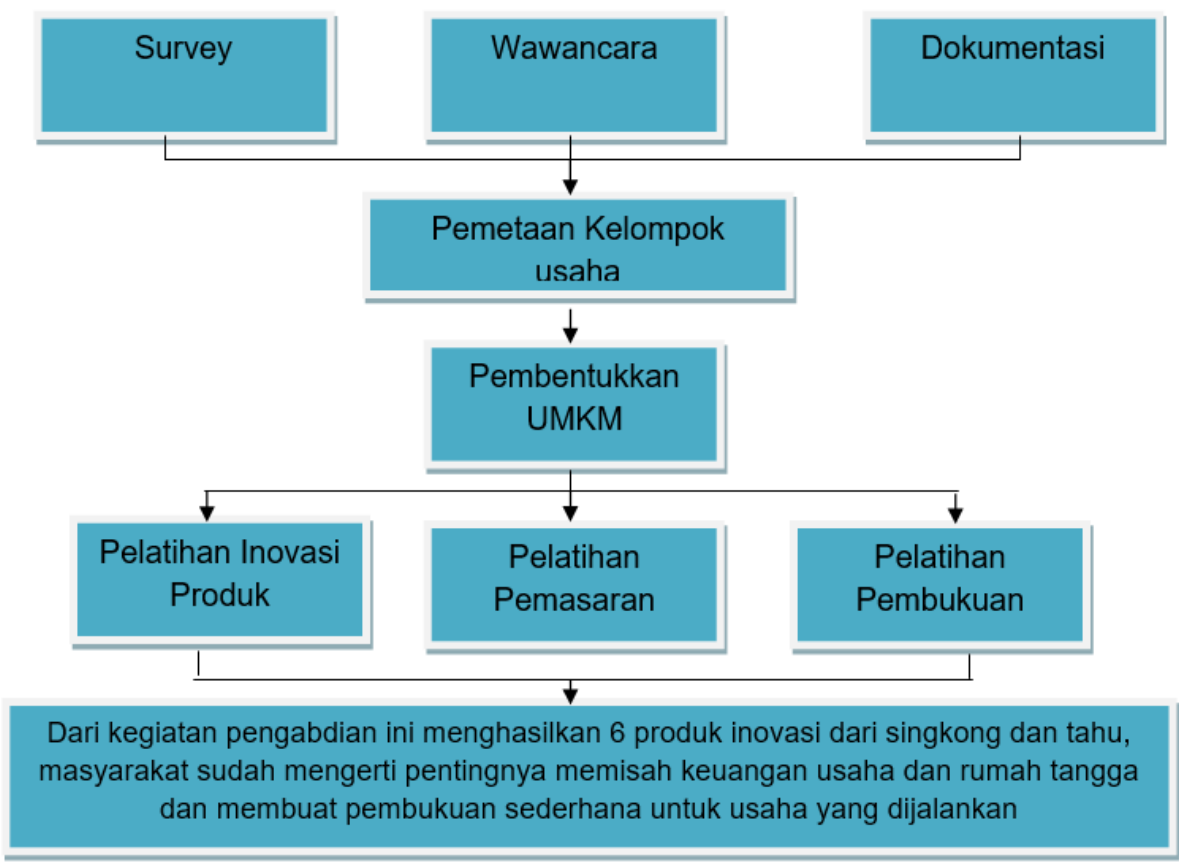

\section{Gambar 1. Metode Pelaksanaan Kegiatan Pengabdian Kepada Masyarakat}

\section{HASIL DAN PEMBAHASAN}

Keberadaan UMKM tidak dapat dihapuskan ataupun dihindarkan dari masyarakat bangsa saat ini. Karena keberadaannya sangat bermanfaat dalam hal pendistribusian pendapatan masyarakat. Selain itu juga mampu menciptakan kreatifitas yang sejalan dengan usaha untuk mempertahankan dan mengembangkan unsur-unsur tradisi dan kebudayaan masyarakat setempat. Pada sisi lain, UMKM mampu menyerap tenaga kerja dalam skala yang besar mengingat jumlah penduduk Indonesia yang besar sehingga hal ini dapat mengurangi tingkat pengangguran. 
Berdasarkan hasil survey dan wawancara yang dilakukan pada para masyarakat pelaku usaha, uraian permasalahan dan solusi kami berikan selama melakukan pengabdian pada masyarakat Desa Tonggorisa Kecamatan Palibelo Kabupaten Bima (Gambar 2), adalah sebagai berikut;

a) Permasalahan permodalan untuk mengembangkan usaha selalu menjadi masalah utama yangdihadapi pelaku usaha, Hal ini juga dirasakan olej pelaku usaha di Desa Tonggorisa apalagi kemampuan masyarakat membeli karena pandemic covid 19 yang semakin menurun. Allhamdulillah pelaku usaha di Desa Tonggorisa mendapatkan bantuan dana BPUM (bantuan produktif usaha mikro)

b) Permasalahan inovasi produk, Usaha yang di lakukan masyarakat di Desa Tonggorisa sebagian besar hanya terbatas pada usaha Kerupuk singkong dengan rasa yang original. Solusi yang kami berikan dengan melalukan pelatihan inovasi produk dengan menjadikan singkong bukan saja sebagai kerupuk tetapi berbagai macam produk seperti, stik singkong, tortilla singkong, kerupuk singkong unyil. Agar potensi yang dimiliki Desa Tonggorisa berupa singkong bisa menjadi produk-produk yang berinovatif dan memiliki nilai jula yang tinggi sehingga ekonomi kreatif masyarakat bisa tercapai

c) Permasalahan pemasaran, Masyarakat masih belum faham tentang bagaimana memasarkan produk yang dapat mempuaskan konsumen. Solusi yang kami berikan dengan melakukan pelatih pemasaran mulai dari memberikan pelatihan cara membuat kemasan yang bagus, adanya label produk dan menggunakan digital marketing sebagai sarana promosi di pasar agar lebih luas.

d) Permasalahan Keuangan. Keuangan para pelaku usaha di Desa Tonggorisa masih memberlakukan keuangan satu dompet yang berarti keuangan rumah tangga di gabung dengan keuangan usaha, sehingga solusi yang kami melakukan dengan member pelatihan pembukuan sederhana untuk memberikan education kepada para pelaku usaha agar mampu memisahkan keuangan rumah tangga dan keuangan usaha supaya jelas berapa pemasukan dari usaha yang dilakukan tiap minggu atau per bulannnya

e) Permasalahan Tenaga Kerja, Generasi muda yang meneruskan usaha di Desa Tonggorisa masih minim, yang menjadi pelaku usaha kebanyakan adalah ibu-ibu yang kesehariannya adalaha ibu rumah tangga. Setelah mereka menyelesaikan urusan rumah tangga baru menjalankan aktivitas usaha dengan memproduksi, Hal ini kan menghambat jumlah produksi jika terjadi permintaan pasar yang tinggi. Hal yang kami lakukan yaitu memberikan motivasi dan pelatihan kepada anak-anak remaja untuk dapat melanjutkan usaha keluarga nya atau memulai usaha baru yang sejenis, makanya dalam pelatihan yang kami laksanakan bukan saja ibu-ibu pelaku usaha yang jadi pesertanya tetapi anakanak remaja juga yang kami libatkan.
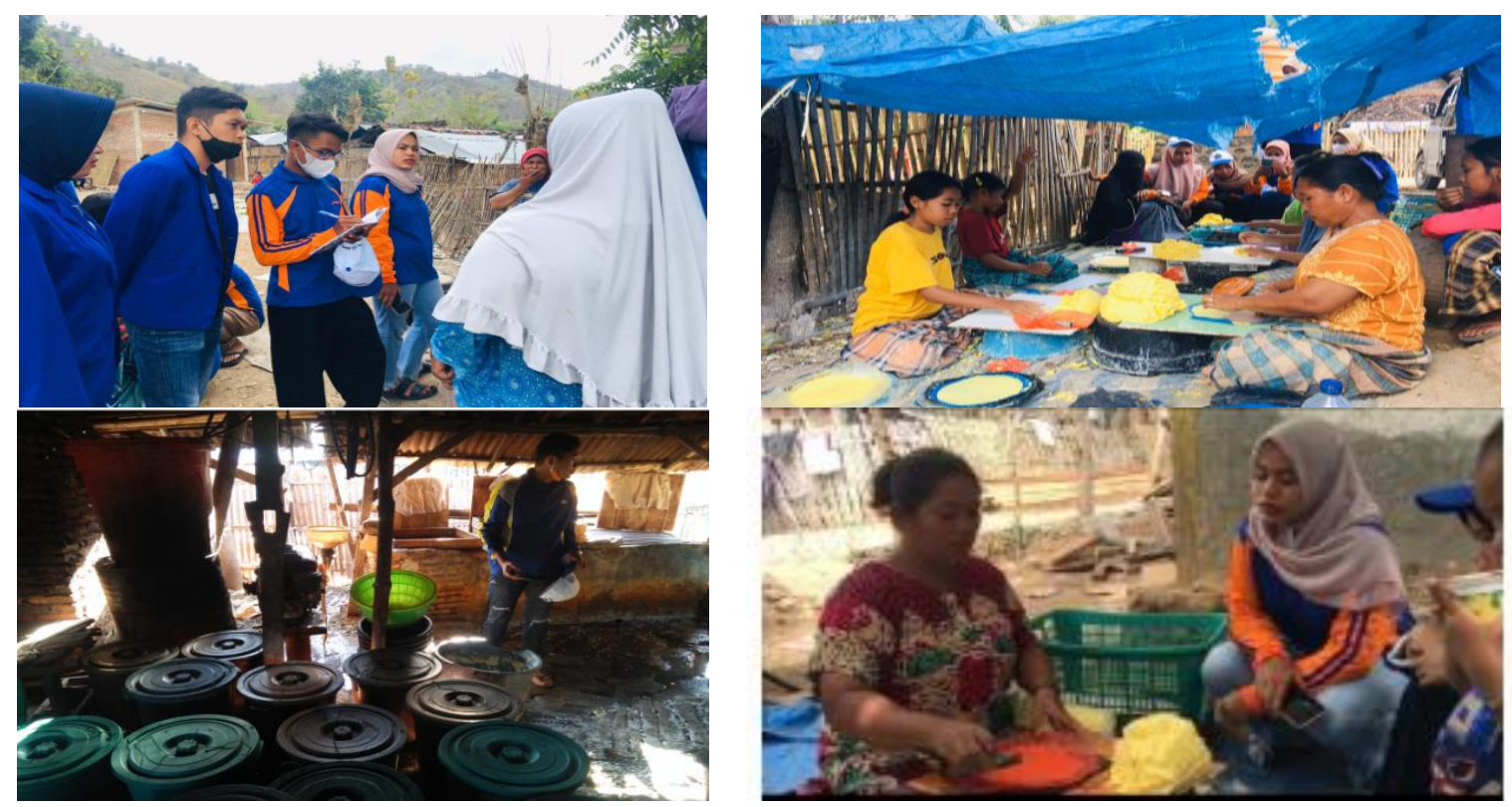

Gambar 2. Kegiatan Survey dan wawancara terhadap pelaku Usaha 
Masyarakat Desa Tonggorisa mempunyai usaha yang sudah berjalan bahkan turun temurun, tetapi belum dikelompokkan, sehinggan dalam pengabdian ini kami membentuk kelompok dan pemetaan kelompok sesuai dengan jenis usaha masyarakat (Tabel 1).

Tabel 1. Data UMKM Desa Tonggorisa Kecamatan Palibelo Kabupaten Bima

\begin{tabular}{|c|c|c|c|c|c|}
\hline NO & NAMA & USAHA & $\mathrm{RT} / \mathrm{RW}$ & $\begin{array}{c}\text { LAMA } \\
\text { BERDIRI }\end{array}$ & NO HP \\
\hline 1 & ST. Nu & Kios & $(01 / 01)$ & 7 tahun & 82340981175 \\
\hline 2 & Rostina & Kios & $(01 / 01)$ & 2 tahun & 82341462325 \\
\hline 3 & Sadia & Kios & $(01 / 01)$ & 25 tahun & 85338384320 \\
\hline 4 & Salma & Karopo Bojo & $(01 / 01)$ & 10 tahun & \\
\hline 5 & ST. Nur & Karopo Bojo & $(01 / 01)$ & 11 tahun & \\
\hline 6 & Hawusa & Karopo Bojo & $(01 / 01)$ & 12 tahun & \\
\hline 7 & ST. Ria & Karopo Bojo & $(01 / 01)$ & 13 tahun & \\
\hline 8 & ST. Mariam & Karopo Bojo & $(01 / 01)$ & 25 tahun & 85237207255 \\
\hline 9 & Astuti Arifuddin & Karopo Bojo & $(01 / 01)$ & 23 tahun & 82340124530 \\
\hline 10 & Fatimah Syarifudin & Karopo Bojo & $(01 / 01)$ & 3 tahun & 82339260558 \\
\hline 11 & Fari & Kios & $(02) /(01)$ & 3 tahun & \\
\hline 12 & Nita & Kios & $(02) /(01)$ & 5 tahun & 85339709061 \\
\hline 13 & Jaleha & Kios & $(02) /(01)$ & 23 tahun & 81380237771 \\
\hline 14 & Rukaya & Kios & $(03 / 01)$ & 5 tahun & 8983137831 \\
\hline 15 & Siti Sia & Kios & $(03 / 01)$ & 11 tahun & 82339542934 \\
\hline 16 & Hasna & Karopo Bojo & $(03 / 01)$ & 3 tahun & 85338533856 \\
\hline 17 & Astika Duhami & Karopo Bojo & $(03 / 01)$ & 27 tahun & 82340124530 \\
\hline 18 & Abdul Hami & Bedek & $(04 / 02)$ & 20 tahun & 82339796249 \\
\hline 19 & Siti Aminah & Kios & $(05 / 02)$ & 15 tahun & 85205789669 \\
\hline 20 & Siti Sah & Kios & $(05 / 02)$ & 2 tahun & 85339114924 \\
\hline 21 & Salmah & Kios & $(06 / 03)$ & 33 tahun & 85253247653 \\
\hline 22 & Nurhairunisah & Kios & $(06 / 03)$ & 5 tahun & 82342746381 \\
\hline 23 & Nur Aini & Kios & $(07 / 04)$ & 4 tahun & 85333697115 \\
\hline 24 & Fatmah & Karopo Bojo & $(07 / 04)$ & 6 tahun & 82339988586 \\
\hline 25 & Siti Hawa & Kios & $(08 / 04)$ & 50 tahun & 85337489836 \\
\hline 26 & Devi Astrianingsih & Kios & $(08 / 04)$ & 3 tahun & 85337500301 \\
\hline 27 & Nurningsih & Kios & $(08 / 04)$ & 20 tahun & 85337073700 \\
\hline 28 & Ariati & Kios & $(08 / 04)$ & 13 tahun & 85338612451 \\
\hline 29 & Nurkaya & Kios & $(08 / 04)$ & 5 tahun & 82342005559 \\
\hline 30 & Astuti & Kios & $(08 / 04)$ & 11 tahun & 85333199059 \\
\hline 31 & Syamsudin & Tahu & $(09 / 04)$ & 12 tahun & \\
\hline 32 & Kalisom & Kios & $(09 / 04)$ & 60 tahun & 82359061562 \\
\hline 33 & Hausa & Kios & $(09 / 04)$ & 4 bulan & 82339492255 \\
\hline 34 & Nuraini & Kios & $(09 / 04)$ & 19 tahun & 85337443215 \\
\hline 35 & Haja Kibitia & Kios & $(09 / 04)$ & 1 tahun & \\
\hline 36 & Siti Nurlaila & Kios & $(09 / 04)$ & 13 tahun & 82342622359 \\
\hline 37 & Hj. Hausa & Kios & $(09 / 04)$ & 6 tahun & \\
\hline
\end{tabular}

Hasil dari kegiatan ini adalah terbentuknya kelompok UMKM sesuai dengan jenis usahanya sebagai pemetaan jenis usaha masyarakat dapat mempermudah pemberdayaan karena setiap UMKM mempunyai permasalahnya yang berbeda sehingaan dengan melakukan pemetaan pemberdayaan melalui pelatihandapat tepat sasatan dan mampu mengatasi masalah yang dialami UMKM tersebut. Tindak lanjut dari pengabdian kami ini adalah 
menjadikan UMKM yang kami bentuk sebagai mitra dalam In-kubator Bisnis yang sudah terbentuk di Sekolah Tinggi Ilmu Ekonomi Bima (Gambar 3 dan 4).
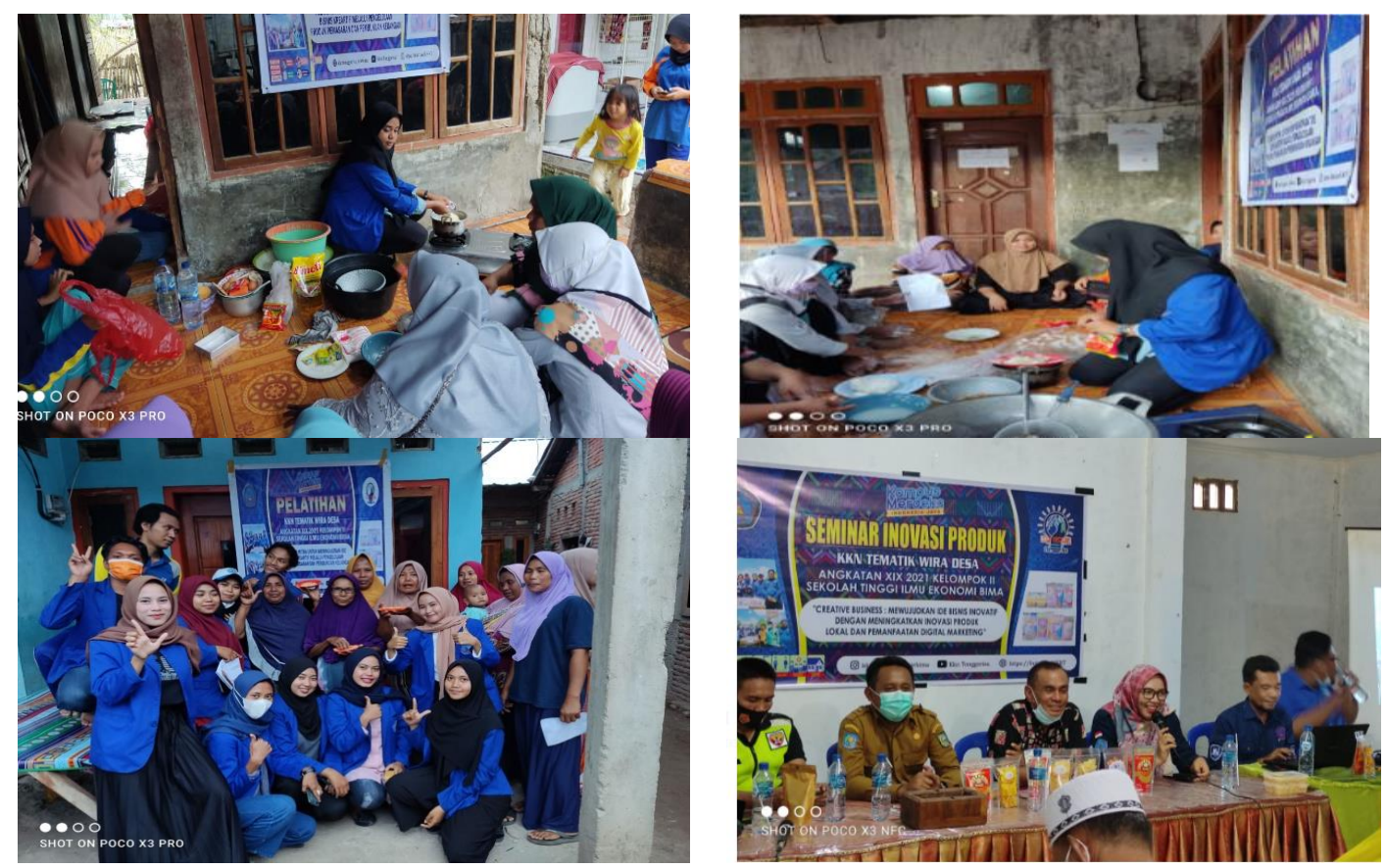

\section{Gambar 3. Kegiatan pelatihan inovasi produk, pemasaran, pembukuan sederhana}
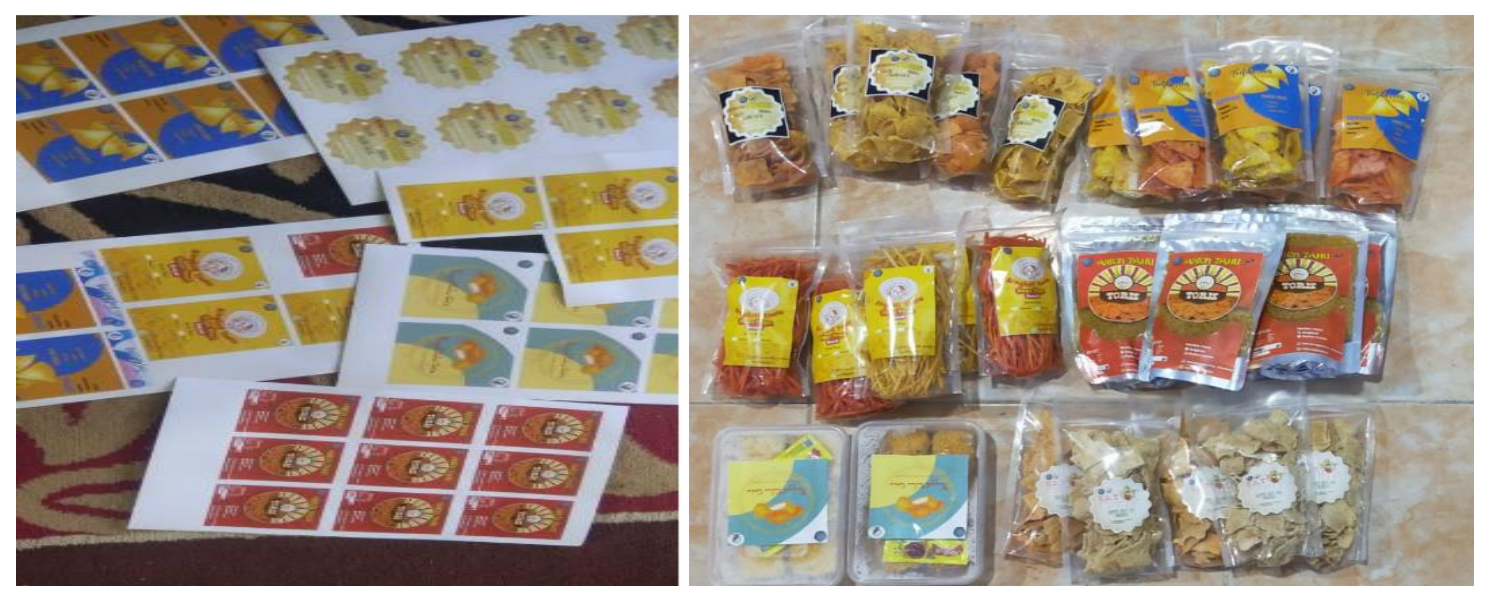

Gambar 4. Hasil produk inovasi dan pemasaran hasil pelatihan

\section{KESIMPULAN}

Kegiatan pengabdian kepada masyarakat yang kami lakukan melalui beberapa tahap seperti survey, wawancara dan dokumentasi, kemudian dilakukan pembentukkan kelompok UMKM dan pemetaan UMKM sesuai dengan jenis usaha untuk mengetahui permasalah yang terjadi dan mencari solusi dari masalah tersebut. Solusi yang kami berikan melalui pengabdian ini yaitu dengan memberikan pelatihan seperti pelatihan inovasi produk, pemasaran, dan pembukuan sederhana. Harapan kami setelah melakukan pengabdian menjadikan Desa Tongorisa bisa menjadi desa sejahtera dan mandiri.

\section{UCAPAN TERIMA KASIH}

Ucapan terima kasih kami ucapkan kepada Yayasan Pendidikan Sinar Jaya Bima, Sekolah Tinggi IImu Ekonomi Bima atas dukungan material dan kesempatannnya dan Pemerintah Kabupaten Bima tepatnya Desa Tonggorisa atas kesediaanya menerima kami untuk melakukan Tri Dharma Perguruan Tinggi yaitu Pengabdian kepada Masyarakat serta masyarakat Desa Tonggorisa yang mejadi mitra dalam pengabdian ini. 


\section{DAFTAR PUSTAKA}

[1] Hartarto, Airlangga dan Muhajir, 2013. Pemberdayaan Koperasi dan UMKM dalam rangka menungkatkan perekonomian masyarakat. www.depkop.go.id/phocadownload/Rakernas_2013/komisi\%20vi\%20dpr-ri.pdf.

[2] Humas Kementerian Koperasi dan UKM, 2021.Seskemenkopukm: Tidak Ada Pengurangan Jumlah Pelaku Usaha Formal Dan Informal Hingga 30 Juta Orang.https://kemenkopukm.go.id/read/seskemenkopukm-tidak-ada-pengurangan-jumlahpelaku-usaha-formal-dan-informal-hingga-30-juta-

orang\#: :text=Sementara\%20jumlah\%20pelaku\%20usaha\%20mikro,05\%20juta\%20orang $\% 20$ pada\%202020

[3] Rizal, 2020. 16.603 UMKM Kabupaten Bima Terima Bantuan Usaha. https://bimakab.go.id/news/172-16603-umkm-kabupaten-bima-terima-bantuan-usaha.

[4] Widjaja Mintarti U.S, Racmawati Dian, Munir Syahrul \& Satrio Dwi Yogi, 2020. Pemberdayaan UMKM Gerabah Melalui Pembentukan Komunitas Pra-Koperasi Di Kabupaten Ponorogo. DINAMISIA: Jurnal Pengabdian Kepada Masyarakat. Vol. 4, No. 1, Hal. 26-35.

[5] Kasih, Yulizar dan Rini Aprilia 2013, The Competitiveness of Indonesian MicroSmallMedium Enterprises (MSMEs) Facing ASEAN Economic Community (AEC) in 2015, Proceeding, ICEISM 2014, p.159.

[6] Cholid Idham, Kasih Yulizar \& Arisman Anton, 2016. Pemberdayaan Usaha Mikro Kelompok Wanita Pengrajin Ikan Salai Di Kota Palembang. Jurnal IImiah STIE MDP. Vol. 6 No. 1. Hal 45-51. 